\section{Cloud-based convenience}

With the CS Softdent Cloud practice management software from Carestream Dental, you can rest assured that no matter how busy you are, you can always work efficiently.

CS Softdent Cloud allows you to access

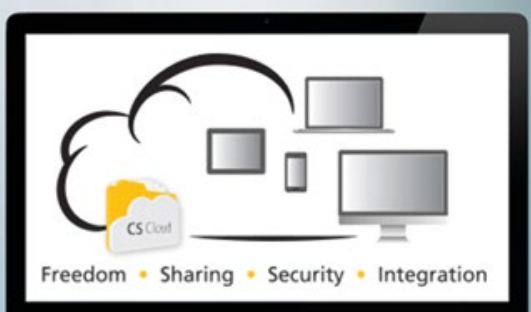
all relevant patient information anytime, anywhere, from any device with an internet connection. This means you can work on cases when you require without being tethered to a single location.

Furthermore, as all of this information is stored in the cloud, it is securely protected against any cyber threats, giving you ultimate peace of mind.

For more information, contact Carestream Dental on 08001699692 or visit www.carestreamdental.co.uk.

\title{
Meet the demand
}

With increasingly high expectations, today's patients want to be confident that you can offer a dental implant that not only functions like a natural tooth, but looks like one too. That's why many clinicians

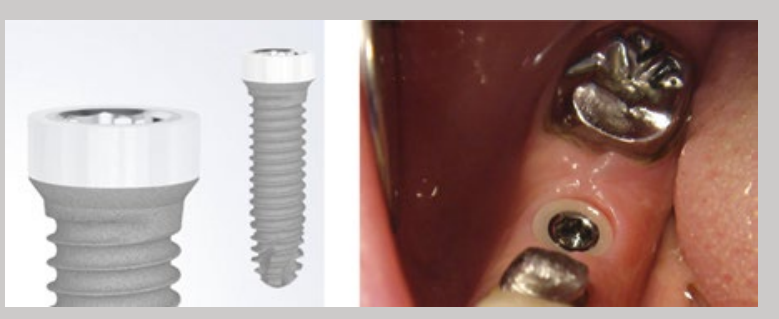

choose the Z1 implant system manufactured by TBR.

The $\mathrm{Z} 1$ remains the world's only tissue-level implant to combine a titanium body with a unique zirconia collar in one seamless component. This cutting-edge design offers excellent hard and soft tissue integrative properties, which enable clinicians to achieve an optimal, natural-looking result. Boasting an impressive $98.6 \%$ success rate, it's no wonder that the $\mathrm{Z} 1$ implant is the first-choice solution for many practitioners.

For more information on the Z1 implant, visit tbr.dental, email support@denkauk.com or call 08007076212 .

\section{Hand care that makes a difference}

Hand hygiene is incredibly important to follow in order to prevent the spread of disease in your dental practice.

So why not ensure pathogens have no chance of transferring to other surfaces by choosing the Steri-7 Xtra range of disinfectants from Initial Medical?

The Personal Care Range includes a hypoallergenic surgical level Hand Rub and Wash. These products can be used in the surgery but also in washrooms and other spaces where germs may be spread. They kill $99.9999 \%$ of pathogens and also have Reactive Barrier Technology

- an innovative feature that prevents pathogens recolonising treated surfaces for up to 72 hours.

For further information visit www.initial. co.uk/medical or Tel: 08708504045.
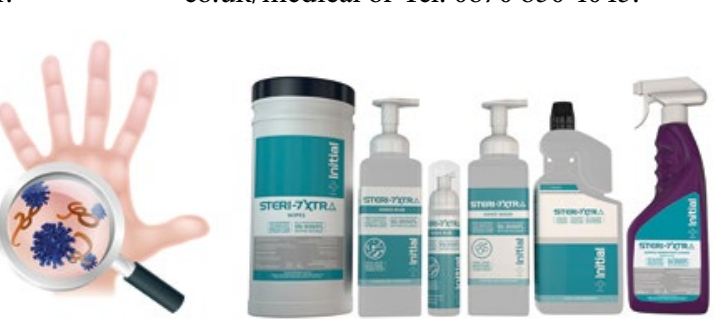

\section{Now available in}

\section{the UK!}

Meisinger products have long been considered some of the most reliable and excellent products on the global market. Now, they're available in the UK.

Through a new subsidiary called myplant, UK professionals can access to the extraordinary catalogue of products on offer, including rotary equipment, dental instruments and more!

In addition, myplant will soon be introducing a new implant system, myplant two, that is based on a trusted 30-year-old formula and perfected to modern day clinical standards.

To find out more about myplant and learn more about the various Meisinger products now available in the UK, visit www.myplantdental.com or call 004921311259465.

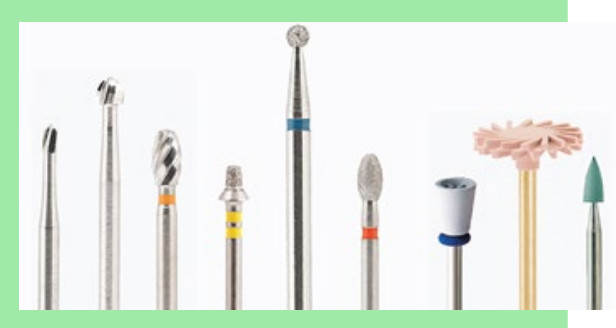

